\title{
Reliability and validity of the EORTC QLQ-C30 in palliative care cancer patients
}

\section{Research Article}

\author{
Hubert R. Jocham ${ }^{1 *}$, Theo Dassen², Guy Widdershoven ${ }^{3}$, Ruud Halfens ${ }^{4}$ \\ ${ }^{1}$ Palliative Care Expert, Head of the Home Care Akademie, \\ 88085 Langenargen, Germany \\ ${ }^{2}$ Department of the Nursing Science, Humboldt University of Berlin, \\ 13353 Berlin, Germany \\ ${ }^{3}$ Faculty of Health Sciences and Scientific, \\ Care and Public Health Research Institute (CAPHRI) Universiteit Maastricht, \\ 6211 Maastricht, Maastricht (Limburg), The Netherlands \\ ${ }^{4}$ Health Care Studies Section Nursing Science, Faculty of Health Sciences, \\ Universiteit Maastricht, 6211 Maastricht, Maastricht (Limburg), The Netherlands
}

Received 11 November 2008; Accepted 29 January 2009

\begin{abstract}
Palliative care aims at improving the patient's quality of life. The assessment of this quality of life (QoL) is crucial for the evaluation of palliative care outcome. Many patients require hospital admissions for symptom control during their cancer journey and most of them die in hospitals, although they would like to stay at home until the end of their lives. In 1986, the European Organization for Research and Treatment (EORTC) initiated a research programme to develop an integrated, modular approach for evaluating the quality of life of patients participating in international clinical trials. This questionnaire measures cancer patients' physical, psychological and social functions and was used in a wide range of clinical cancer trials with large numbers of research groups and also in various other nontrial studies. The aim of this study was to evaluate the psychometric properties, especially the reliability, validity and applicability of the EORTC QLQ-C30 in a German sample of terminally ill cancer patients receiving palliative care in different settings. The questionnaire was well accepted in the present patient population. Scale reliability was good (pre-treatment 0.80 ) especially for the functional scale. The results support the reliability and validity of the QLQ-C30 (version 3.0) as a measure of the health-related quality of life in German cancer patients receiving palliative care treatment.
\end{abstract}

Keywords: EORTC QLQ C3O • Health-related quality of life • Palliative care • Cancer • Nursing research

(c) Versita Warsaw and Springer-Verlag Berlin Heidelberg.

\section{Introduction}

Palliative care is defined by the World Health Organization as an approach that improves the quality of life of patients and their families, whom face problems associated with life-threatening illness, through the prevention and relief of suffering by means of early identification, impeccable assessment and treatment of pain and other physical, psychosocial and spiritual problems. Palliative care:

- $\quad$ provides relief from pain and other distressing symptoms;

- $\quad$ affirms life and regards dying as a normal process;
- $\quad$ intends neither to hasten nor postpone death;

- integrates the psychological and spiritual aspects of patient care;

- $\quad$ offers a support system to help patients live as actively as possible until death;

- $\quad$ offers a support system to help the family cope during the patients illness and in their own bereavement;

- uses a team approach to address the needs of patients and their families, including bereavement counselling, if indicated;

- $\quad$ will enhance quality of life, and may also positively influence the course of illness; 
- is applicable early in the course of illness, in conjunction with other therapies that are intended to prolong life, such as chemotherapy or radiation therapy, and includes those investigations needed to better understand and manage distressing clinical complications.

Therefore, there is a wide scope for research. In addition, there is also a need for research into the management and organisation of services and their quality of care. In recent years, attention on palliative care has a considerable increase in most European Countries in all areas of health care. As palliative care emerges it is becoming clear that it needs to take place in a wide range of settings, e.g., hospital, hospice, nursing home, day care and patients' homes. In Germany the progression in this specialty is far behind the advancements, i.e., the UK. Currently, there is a reorganisation in the German health care system. There is the official political principle that home care is primary to hospital or nursing home care, thus, in the next few years, there will be a reduction in hospital beds by one-third, which will enforce a rapid change from hospital to home care. German politicians have yet to find a solution to transfer the high quality of palliative care from the established settings, i.e., hospice or palliative care units to the community environment. The new situation and the demand for more specialised palliative care teams increase the need for evaluation of the effect and quality of care.

Health-related quality of life assessment in cancer patients has attracted an increasing interest in recent years, particularly in the oncology nursing discipline. There it includes an assessment of the impact of the disease and its treatment on the physical, psychological and social functioning of the patient [2]. Many excellent validated self-completion questionnaires to measure HRQOL for patients with cancer are available, e.g., EORTC QLQ-C30, Functional Assessment of Cancer Therapy (FACT) (Holzner, Kemmler et al. 2004) [30], Rotterdam Symptom Checklist (RSCL) (Hardy, Edmonds et al. 1999)[28] and Functional Living IndexCancer (FLIC) (Annunziata, Foladore et al. 1998; Kuenstner, Langelotz et al. 2002)[5,40]. Other relevant instruments for palliative care include the Support Team Assessment Scale (STAS) (Carson, Fitch et al. 2000)[16], the McMaster Quality of Life Scale (MQLS) (Sterkenburg, King et al. 1996)[52] and the Symptom Distress Scale (SDS) (Heedman and Strang 2001) [29]. All those questionnaires are multidimensional, covering a minimum of the physical, psychological and social domains as well as some overall judgements of the validation of life or the health condition. It is hardly necessary (or advisable) to develop more or new instruments, but there should be clear recommendations and guidelines on which instruments are capturing the most relevant issues of concern for people with palliative care needs although there has been much criticism of the EORTC QLQ-C30 for use in palliative care by not covering important domains (e.g. spirituality).

In 1986, the European Organization for Research and Treatment of Cancer (EORTC) study group on quality of life initiated a research programme the longterm objective of which was to develop an integrated measure system for evaluating the HRQOL of patients participating in international clinical trials (Aaronson, Ahmedzai et al. 1993)[1].

Systematic evaluation of health-related quality of life (HRQoL) could enable clinicians to identify patients who are at an increased risk of encountering psychosocial problems, so that appropriate intervention strategies can be initiated where necessary (Bliss and While 2003) [13]. Sufficient validity and reliability are mandatory for any measuring tools (Kaasa, Bjordal et al. 1995; Klee, Groenvold et al. 1997; Sprangers, Cull et al. 1998) $[33,37,50]$ especially for the use in palliative care with terminally ill patients.

The EORTC quality of life questionnaire is an integral system for assessing the HRQoL of cancer patients. A first-generation core questionnaire, the EORTC QLQ C36, was developed in 1987 by Aaronson and Beckmann (Beckmann, Betsholtz et al. 1988) [10]. The EORTC QLQ-C30 is a second-generation questionnaire. It is a 30-item questionnaire with a 4-point answer scale. Following its general release in 1993 (Aaronson, Ahmedzai et al. 1993)[1], the QLQ-C30 was used in a wide range of clinical cancer trials by a large number of research groups (Anderson, Aaronson et al. 1996; De Boer, Sprangers et al. 1996; Curran, Fossa et al. 1997; Curran, van Dongen et al. 1998; Kiebert, Curran et al. 1998; Langendijk, Aaronson et al. 2000; de Haes, Curran et al. 2003)[1,4,20,21,23,35,42,50] and was additionally used in various other non-trial studies (Ahmedzai and Brooks 1997; Stromgren, Groenvold et al. 2001; Bestall, Ahmed et al. 2004)[2,11,54]. The EORTC QLQ-C30 has been designed for use in a range of languages and cultures, the validation of the QLQ-C30 specific to a German population and the development of disease-specific modules to supplement the EORTC QLQ-C30. Patients receiving palliative care treatment are usually in an end-stage situation on their illness, in this study cancer. At present, they have received curative treatments, which include chemotherapy, hormontherapy, radiotherapy and surgery. But when the cancer deteriorates under these therapies and no other possibilities did help, the palliative care treatment increasingly became the centre of clinical possibilities. 
Palliative care comes from the Latin word palliare, which means to put a coat at some ones body. At present, symptom control is standing in the centre of attention and not the healing of the cancer. Palliative care emerges as an important field in health care; it takes place in a wide range of settings, e.g., hospital, hospice, nursing home and patient's home. People being terminally ill have a specific set of circumstances. Active therapy being received is not being offered with curative intent. Physical deterioration has come to affect everyday functioning, and deterioration has become progressive and irreversible. Survival is likely to be counted in weeks and months rather than years. These problems are those that face health care practitioners, which are responsible for setting standards, developing valid and reliable methods of assessing that standard and being able to use these findings for informing policymakers and healthcare authorities. However, little information is available regarding the psychometric properties of the EORTC QLQ-C30 in such a terminally ill cancer patient population, when used in different care settings (Kaasa, Bjordal et al. 1995; Klee, Groenvold et al. 1997; Sprangers, Cull et al. 1998)[33.37,50].

Therefore, this study is developed to evaluate the psychometricpropertiesand tolookattheappropriateness, relevance, feasibility and responsiveness to change of the EORTC QLQ-C30 in terminally ill patients receiving palliative care in hospital care and in home care.

\section{Material and Methods}

A descriptive study design is utilised to assess the practicality, reliability and validity of the EORTC QLQ-C30 (version 3.0) questionnaire with regard to a German sample of terminally ill cancer patients receiving palliative care either in hospital or at home.

Patients of a general hospital and ten specialised palliative home care services completed a questionnaire for the study upon admission to the service and again after a week of palliative symptom control.

\subsection{Patients}

The study was performed at a cancer care unit of a German general hospital and in 10 specialised palliative home care services in South Germany. The 1000-bed hospital has a palliative care unit on an oncology ward. The specialised palliative home care services are hospital-based, which means that they are allocated in the hospitals, they are part of them, they get paid by them but they spend most of their time outside the hospital, in the homes of the patients. This kind of service is very exclusive traditionally these are two different sectors in the German health care system. Most of these services have been operating for about 15 years. The home care teams are specially trained nurses who are visiting the patients and their families at their homes and take over responsibility together with the general practitioners. With the support from the home care teams, patients who all suffer from end-stage cancer, are able to stay at home and do not have to be admitted to a hospital for symptom control. Patients are treated for pain relief and management of other cancer-related symptoms like dyspnoea, fatigue, constipation, diarrhoea, nausea, vomiting and anorexia. A stratified random sample (Polit and Sherman 1990)[48] of 121 patients was extracted from a total of 250 cancer patients, who were treated in the hospital or home care services. Every second patient was selected on basis of the performance status, if the inclusion criteria were fulfilled. Inclusion criteria were: older then 18 years, no cerebral metastases, no known psychiatric disorder, a Karnofsky performance status (Karnofsky 1968; Schaafsma and Osoba 1994) $[34,49]$ of not less than $40 \%$, cognitive capability to fill in the questionnaire and a good command of the German language. All participating patients were no longer under anticancer treatment. Prior to completing the questionnaire all patients who agreed to participate, signed an informed consent after they and their next of kin had received detailed information. The study was approved by the local medical ethics committee.

\subsection{Instrument}

Demographic and clinical data were recorded by the study investigators or the staff on a separate sheet. The health-related quality of life was measured with the EORTC QLQ-C30. The EORTC QLQ-C30 was designed to cover several aspects of the patient's healthrelated quality of life (physical as well as psychosocial aspects). The 30-item EORTC QLQ-C30 deals with the health and well-being in the past week. Each item can be scored on a 4-point scale: not a problem; a little; quite a bit; and, very much. The responses regarding the items are converted to a 0-100 scale. The 30 items are divided into 6 functional scales: physical function (5 questions); social function (2 questions); role function (2 questions); emotional function (4 questions); cognitive function (2 questions); global health status/ QoL (2 questions) and 3 scales comprising fatigue (3 questions); pain (2 questions); nausea and vomiting scales (2 questions) and 6 items about symptoms (lack of appetite, constipation, diarrhoea, dyspnoea, insomnia and financial difficulties). Scores on items of each scale are summated to one total score. A high score on each scale represents a high level in the examined topic, a high score on the global health status/ 
Table 1. Content of the QLQ-C30 dimensions scales and single item scales.

\begin{tabular}{|c|c|c|c|c|}
\hline \multirow[t]{3}{*}{ Content } & \multirow[t]{3}{*}{ Qol dimension } & \multirow[t]{3}{*}{$\begin{array}{l}\text { No. of } \\
\text { questions }\end{array}$} & \multicolumn{2}{|c|}{$\begin{array}{l}\text { Literal interpretation of the lowest and highest scores: } \\
\qquad \text { In the past week I was......... }\end{array}$} \\
\hline & & & Lowest possible $=0$ & Highest possible $=100$ \\
\hline & & & Questions & \\
\hline \multirow[t]{2}{*}{ Global } & Global QoL & 2 & Overall physical condition and & Overall physical condition and \\
\hline & & & Quality of life was very poor & Quality of life was excellent \\
\hline \multirow[t]{5}{*}{ Functional } & Physical Function & 5 & $\begin{array}{l}\text { Was confined to bed, needed help with } \\
\text { dressing, washing and eating }\end{array}$ & Was able to do strenuous physical activities \\
\hline & Role Function & 2 & $\begin{array}{l}\text { Was completely unable to work at a job or do } \\
\text { household jobs }\end{array}$ & $\begin{array}{l}\text { Was not limited at all in doing either work or } \\
\text { household jobs }\end{array}$ \\
\hline & Emotional Function & 4 & $\begin{array}{l}\text { Felt very tense, irritable and depressed and } \\
\text { worried a lot }\end{array}$ & $\begin{array}{l}\text { Did not feel at all tense, irritable or depressed } \\
\text { and did not worry at all }\end{array}$ \\
\hline & Social Function & 2 & $\begin{array}{l}\text { Physical condition and medical treatment } \\
\text { interfered very much with family life and social } \\
\text { activities }\end{array}$ & $\begin{array}{l}\text { Physical condition and medical treatment did } \\
\text { not interfere at all with family life and social } \\
\text { activities }\end{array}$ \\
\hline & Cognitive Function & 2 & $\begin{array}{l}\text { Had a lot of difficulty with concentrating and } \\
\text { remembering things }\end{array}$ & $\begin{array}{l}\text { Did not have any difficulty with concentrating } \\
\text { or remembering things }\end{array}$ \\
\hline \multirow[t]{3}{*}{ Symptoms } & Nausea and Vomiting & 2 & Did not feel at all nauseous and did not vomit & Felt very nauseous and vomited frequently \\
\hline & Pain & 2 & $\begin{array}{l}\text { Did not have any pain, and pain did not } \\
\text { interfere at all with daily activities }\end{array}$ & $\begin{array}{l}\text { Had a lot of pain which interfered strongly with } \\
\text { daily activities }\end{array}$ \\
\hline & Fatigue & 3 & $\begin{array}{l}\text { Did not feel at all weak or tired and did not } \\
\text { need to rest at all }\end{array}$ & $\begin{array}{l}\text { Felt very weak and tired and needed to rest } \\
\text { a lot }\end{array}$ \\
\hline \multirow[t]{6}{*}{ Single items } & Constipation & 1 & Have you been constipated? & Felt very constipated \\
\hline & Diarrhoea & 1 & Have you had diarrhoea? & Have diarrhoea many time a day \\
\hline & Sleep & 1 & Have you had trouble sleeping? & Have a lot sleeping probelms \\
\hline & Dyspnoea & 1 & Were you short of breath & I am breathless most of the time \\
\hline & Appetite & 1 & Have you lacked appetie? & Have appetite loss most of the time \\
\hline & Financial & 1 & $\begin{array}{l}\text { Has your physical condition caused you } \\
\text { financial difficulties? }\end{array}$ & Have a lot of financial problems \\
\hline
\end{tabular}

QoL for instance represents a high QoL and a high score in a symptom scale/item represents a high level of symptomatology/problems. (Table 1)

The staff of the palliative care unit, the home care teams and the study investigator additionally recorded data according to the applicability and practicality of the quality of life instrument. They asked patients how long it took them to answer all questions, and about any inconvenience and burden. Finally, the investigators expressed their opinion on how much pressure those questions put on the patients. An additional questionnaire with open-ended questions was used to obtain information about the appropriateness and feasibility of the instrument.

\subsection{Procedure}

Patients were asked to complete the first questionnaire within the first 24 hours upon admission to the unit or home care services. All patients were given brief instructions on how to complete the questionnaire. The staff of the palliative care unit, the home care teams and the study investigator were available for questions regarding the study and the completion of the forms.

\subsection{Data analysis}

All statistical procedures were performed in accordance with the instructions contained in the EORTC QLQ-C30 scoring manual (Arraras, Arias et al. 2002; Fayers and Bottomley 2002)[6,26].

Average values of descriptive methods, standard deviations for the continuous variables and frequencies and percentages for the categorical variables were used to describe the data. For the examination of the construct validity of the QLQ-C30 principal components analysis was carried out, To evaluate the internal consistency of the EORTC QLQ-C30 the Cronbach's alpha coefficients were calculated (Table 4). Using Pearson's coefficient of correlation between the QLQ-C30 dimensions as a 
Table 2. Patients' sociodemographic and medical characteristics.

\begin{tabular}{|c|c|c|c|}
\hline & Total sample $(n=121)$ & Home Care $(n=64)$ & Hospital Care $(n=57)$ \\
\hline \multicolumn{4}{|l|}{ Gender } \\
\hline Females & $70 \quad(57.8 \%)$ & $35 \quad(61.4 \%)$ & $35 \quad(54.7 \%)$ \\
\hline Males & $51 \quad(42.2 \%)$ & $22 \quad(38.6 \%)$ & $29 \quad(35.3 \%)$ \\
\hline Age (years) & $35-94$ & $38.5-84.4$ & $35-94$ \\
\hline Age (mean) & 63.1 & 61.7 & 64.4 \\
\hline Karnofsky Index (Mean) & 48.5 & 50.7 & 46.6 \\
\hline \multicolumn{4}{|l|}{ Living situation } \\
\hline Alone & 39 & 15 & 24 \\
\hline With spouse or partner & 76 & 45 & 31 \\
\hline With others & 6 & 4 & 2 \\
\hline \multicolumn{4}{|l|}{ Cancer origin } \\
\hline Gastrointestine & 38 & 19 & 19 \\
\hline Lung & 21 & 8 & 13 \\
\hline Breast & 21 & 14 & 7 \\
\hline Male genitals and female genitals & 23 & 12 & 11 \\
\hline Others & 18 & 11 & 7 \\
\hline
\end{tabular}

Table 3. Descriptive statistics.

\begin{tabular}{l|lll}
\hline & Items (1) & Mean score & S.D. \\
\hline \hline Physical function & $1,2,3,4,5$ & 30.86 & 24.41 \\
New role function & 6,7 & 21.69 & 22.81 \\
Emotional function & $21-24$ & 41.34 & 23.23 \\
Cognitive function & 20,25 & 58.56 & 30.34 \\
Social function & 26,27 & 38.47 & 29.88 \\
New global health/Quality & 29,30 & 31.56 & 19.07 \\
of life & & & \\
Fatigue & $10,12,18$ & 72.50 & 21.19 \\
Nausea and vomiting & 14,15 & 46.30 & 33.65 \\
Pain & 9,19 & 60.72 & 31.93 \\
Dyspnoea & 8 & 61.49 & 35.29 \\
Sleep disturbance & 11 & 55.65 & 32.99 \\
Lack of appetite & 13 & 64.79 & 30.00 \\
Constipation & 16 & 36.61 & 36.17 \\
Diarrhoea & 17 & 16.78 & 31.08 \\
Financial Impact & 28 & 32.99 & 33.52 \\
Karnofsky & & 48.50 & 13.10 \\
\hline
\end{tabular}

1.Numbers correspond to the item numbers in the questionnaire 2.scores range from 0-100 with a high score representing a higher level of functioning

3.scores range from 0-100 with a high score representing a greater degree of symptoms

patient perspective and the Karnofsky index as an expert perspective construct validity was calculated (Table 5). There was no need to omit any cases from the analysis due to missing data because all questionnaires from the selected patients have been fully answered. The statistical software SPSS PC for Windows (version 11) was used in the statistical analysis.

\section{Results}

\subsection{Demographic characteristics}

The patient sample consisted of 64 patients in the hospital group and 57 in the home care group, with in total 51 males $(42.2 \%)$ and 70 females (57.8\%). Within the hospital sample, there were 29 males $(35.3 \%)$ and 35 females (54.7\%), and within the home care sample, there were 22 male (38.6\%) and 35 female (61.4\%). The mean age was of 63.1 years (range 35-94 years) in the total sample. The mean age of the hospital group is 64.4 years and of the home care group it was 61.7 years. The mean Karnofsky Index of the total group was 48.5 (range $40-90$, mean of 46.6 in the hospital group and 50.7 in the home care setting). The most prevalent diagnoses were gastro-intestinal cancer (31\%), urogenital cancer $(19.3 \%)$, lung cancer $(17.4 \%)$, breast cancer $(17.4 \%)$ and other cancer sites $(15.1 \%)$ (See Table 2). The majority of the total sample $(n=76)$ lived together with their partners and 39 patients lived on their own at the time of assessment.

\subsection{Description of the scales}

In the functional scales cognition was rated highest with a mean value of 58.6, the new role function lowest with a mean value of 21.7 and in the symptom scales fatigue was rated highest with a mean value of 72.5 , lack of appetite with 64.8 followed by dyspnoea with 61.5 and pain with 60.7 (See Table 3). 
Table 4. Reliability Cronbach's alpha

\begin{tabular}{l|ll}
\hline & Number & Cronbach's alpha \\
\hline \hline Functional scale & 5 & 0.80 \\
Symptoms scale & 3 & 0.63 \\
Single symptoms & 6 & 0.10 \\
\hline
\end{tabular}

\subsection{Applicability and practicality}

The mean time required to complete the QLQ-C30 (version 3.0) was 9 minutes (range 7-15 minutes). No patient reported any difficulty or confusion regarding the questionnaire items. All 250 patients have been able to answer the questionnaire by themselves without excessive use in time and strength for completion.

\subsection{Psychometric testing of the instrument} 3.4.1. Cronbach's a

Cronbach's $\alpha$ was calculated for the a-priori considered dimensions of the QLQ-C30 to explore reliability. The reliability coefficients (Chronbach's Alpha) for the functional scales was 0.80 and for the symptom scales 0.63 . Chronbach's alpha for the single symptom items was very low (Table 4).

\subsubsection{Pearson Correlation}

Although the correlation between the Karnofsky Index and the dimensions of the QLQ-C30 were significant, only the functional scale (0.44) and the global item (0.54) showed a medium association, whilst there was only little to none association regarding the symptom scale (0.18), which reveals that only parts of the patients' view on LQ were covered by an external view. The strongest correlation upon was observed between physical functions and symptoms. Substantial correlation $(>0.40)$ was also noted between the physical functions scale, emotional functions, social functions and the quality of life item. Conversely, a relatively weak correlation was observed between the nausea/vomiting scale and the functional scales. In general, the inter-scale correlation

Table 5. Correlation matrix (Pearson) $n=121$. was of a moderate degree only, indicating that although related they were assessing distinct components of the quality of life instrument.

\section{Discussion}

An increasing number of clinicians use the QLQ-C30 for assessing and monitoring patients in routine clinical practice. The study showed that the questionnaire was well accepted in the present patient population. Well to the point that even the elderly patients and those with terminal illness have little problems in evaluating their HRQOL. In a recent published study in patients with advanced cancer and a median life expectancy of 2 months, it was shown that patients completed QOL measures such as the EORTC QLQ C-30 until the last 1-2 weeks of life (Stromgren and Groenvold, 2002) [53]. Scale reliability was sufficient, especially for the functional scale and the symptom scales, not so for the single symptom scales. High validity was also found in the statistical approaches used. The availability of the questionnaire in a large number of languages opens new ways for comparing samples all around the globe and also enhances the effectiveness of different palliative care services (Kobayashi, Takeda et al. 1998; Mercier, Bonneterre et al. 1998; Zhao and Kanda 2000; Kyriaki, Eleni et al. 2001; Klepstad, Loge et al. 2002; Chie, Chang et al. 2003; Conroy, Mercier et al. 2004; Morita, Shimozuma et al. 2004; Yun, Park et al. 2004) $[17,19,38,39,41,43,44,58,59]$. As stated in the WHO definition of palliative care, its goal is the achievement of the best possible QOL for patients and their families. The use of QOL as an outcome is therefore selfexplanatory.

Many patients of the sample reported positive experience because they were given the opportunity to talk about their health and illness experiences. The weakest scale from a psychometric perspective is

\begin{tabular}{|c|c|c|c|c|c|}
\hline & & Karnofsky Index & New global health/ & Symptomsscale & Functional scale \\
\hline & & & \multicolumn{3}{|l|}{ Quality of life } \\
\hline \multirow[t]{2}{*}{ Karnofsky Index } & & 1 & & & \\
\hline & $\mathrm{N}$ & 121 & & & \\
\hline \multirow[t]{2}{*}{ New global health/Quality of life } & & $.54(* \star)$ & 1 & & \\
\hline & $\mathrm{N}$ & 121 & 121 & & \\
\hline \multirow[t]{2}{*}{ Symptoms scale } & & $-.18\left(^{\star}\right)$ & $-.32\left({ }^{\star \star}\right)$ & 1 & \\
\hline & $\mathrm{N}$ & 121 & 121 & 121 & \\
\hline \multirow[t]{2}{*}{ Functional scale } & & $.44(* \star)$ & $.56\left(^{\star \star}\right)$ & $-.52\left({ }^{* *}\right)$ & 1 \\
\hline & $\mathrm{N}$ & 121 & 121 & 121 & 121 \\
\hline
\end{tabular}

** The correlation on the niveau of 0,01 is significant.

* The correlation on the niveau of 0,05 is significant. 
the financial impact scale and it should be discussed whether it is still necessary for the study population. Some of the items are less relevant in their situation. For example, the question about trouble doing strenuous activities is largely irrelevant to these patients. It could also be suggested, for example, that when assessing these patients the emotional function (EF) scale can be shortened from the original four items to three of only two. The tests of validity yielded generally consistent results. In addition to previously conducted validation studies (Aaronson et al. 1993)[1] of EORTC QLQ C-30 the sample was not restricted to one specific type of cancer but included a wide variety of diagnoses in different palliative care settings. The measurement showed the requirement to also introduce the patients' view when evaluating $L Q$ apart from the already existing measurement of the Karnofsky Index, which is rated by the professionals (Schaafsma and Osoba 1994) [49]. This was indicated in a number of studies that recorded low levels of reliability in the professionals' performance status ratings and low levels of agreement between ratings provided by professionals and those provided by their patients (Schaafsma and Osoba 1994; Stromgren, Groenvold et al. 2002)[49,53]. Therefore, functionally oriented aspects of HRQOL could anticipate even greater problems when assessing subjective experiences, e.g. pain and fatigue (Campbell and Hately 2000; Steer, Marx et al.. 2001; Stromgren, Groenvold et al. 2002; Bostrom, Hinic et al. 2003)[14,15,51,53]. However, there is also an increasing recognition of the need to more systematically assess the impact of cancer and its treatment on the functional, psychological and social health of the patient (Balmer, Thomas et al. 2001; Newbury 2002; Douglas, Halliday et al. 2003; Hughes, Aspinal et al. 2003)[8,24,31,46].

\section{Conclusions}

The EORTC QLQ-C30 has been used in palliative care research and is one of the most widely used instruments for assessing physical and psychosocial symptoms and functionality of patients with cancer, in both curative and palliative settings. The major strengths of the German version of the EORTC QLQ-C30 (version 3.0) are that its formerly satisfactory psychometric properties were found to be valid and reliable. The study yielded results that generally satisfied the conventional psychometric criteria before palliative care treatment. No cases had to be omitted from the analysis due to missing data and there was a high degree of compliance, which indicates that the format and the content of the questionnaire were acceptable for patients with an advanced malignant disease in need for palliative care, both in hospital and in home care settings. On the other hand, possible limitations could be the relatively small sample and a "good" performance status and the criticism, that the QLQ-C30 did not cover all important domains of terminally ill cancer patients, specifically spiritual. The results presume that the QLQ-C30 reliably and validly measures the HRQOL of German cancer patients under palliative care. We consider this version effective in the German palliative care settings as an outcome measurement and for assessing the HRQOL of advanced-stage cancer patients in international clinical trials. Studies with more study periods and larger sample sizes are needed to confirm our results and to allow their generalisation. Further results of the study will be published in additional papers, as part of a doctoral programme in nursing science.

\section{Acknowledgements}

This study was supported by a grant from Robert Bosch Foundation Stuttgart Germany. nr.32.5.1321.0020.0

\section{References}

[1] Aaronson, N. K., S. Ahmedzai, et al. (1993). "The European Organization for Research and Treatment of Cancer QLQ-C30: a quality-of-life instrument for use in international clinical trials in oncology." J Natl Cancer Inst 85(5): 365-76

[2] Ahmedzai, S. and D. Brooks (1997). "Transdermal fentanyl versus sustained-release oral morphine in cancer pain: preference, efficacy, and quality of life. The TTS-Fentanyl Comparative Trial Group." J Pain Symptom Manage 13(5): 254-61
[3] Ahmedzai, S. H., A. Costa, et al. (2004). "A new international framework for palliative care." Eur J Cancer 40(15): 2192-200

[4] Anderson, R. T., N. K. Aaronson, et al. (1996). "A review of the progress towards developing healthrelated quality-of-life instruments for international clinical studies and outcomes research." Pharmacoeconomics 10(4): 336-55

[5] Annunziata, M. A., S. Foladore, et al. (1998). "Does the information level of cancer patients correlate 
with quality of life? A prospective study." Tumori 84(6): 619-23

[6] Arraras, J. I., F. Arias, et al. (2002). "The EORTC QLQ-C30 (version 3.0) Quality of Life questionnaire: validation study for Spain with head and neck cancer patients." Psychooncology 11(3): 249-56

[7] Astradsson, E., L. Granath, et al. (2001). "Cancer patients hospitalised for palliative reasons. Symptoms and needs presented at a university hospital." Support Care Cancer 9(2): 97-102

[8] Balmer, C. E., P. Thomas, et al. (2001). "Who wants second-line, palliative chemotherapy?" Psychooncology 10(5): 410-8

[9] Beck, D. and D. Kettler (2001). "[Symptom control in palliative medicine]." Schmerz 15(5): 320-32

[10] Beckmann, M. P., C. Betsholtz, et al. (1988). "Comparison of biological properties and transforming potential of human PDGF-A and PDGF-B chains." Science 241(4871): 1346-9

[11] Bestall, J. C., N. Ahmed, et al. (2004). "Access and referral to specialist palliative care: patients' and professionals' experiences." Int J Palliat Nurs 10(8): 381-9

[12] Bland,J.M.(1997). Statistics notes: Cronbach's alpha. British Medical Journal 310,170,page 572

[13] Bliss, J. and A. While (2003). "Decision-making in palliative and continuing care in the community: an analysis of the published literature with reference to the context of UK care provision." Int J Nurs Stud 40(8): 881-8

[14] Bostrom, B., H. Hinic, et al. (2003). "Pain and healthrelated quality of life among cancer patients in final stage of life: a comparison between two palliative care teams." J Nurs Manag 11(3): 189-96

[15] Campbell, T. and J. Hately (2000). "The management of nausea and vomiting in advanced cancer." Int J Palliat Nurs 6(1): 18-25

[16] Carson, M. G., M. I. Fitch, et al. (2000). "Measuring patient outcomes in palliative care: a reliability and validity study of the Support Team Assessment Schedule." Palliat Med 14(1): 25-36

[17] Chie, W. C., K. J. Chang, et al. (2003). "Quality of life of breast cancer patients in Taiwan: validation of the Taiwan Chinese version of the EORTC QLQ-C30 and EORTC QLQ-BR23." Psychooncology 12(7): 729-35

[18] Clark, D., H. Malson, et al. (1997). "Needs assessment and palliative care: the views of providers." J Public Health Med 19(4): 437-42

[19] Conroy, T., M. Mercier, et al. (2004). "French version of FACT-G: validation and comparison with other cancer-specific instruments." Eur J Cancer 40(15): 2243-52
[20] Curran, D., S. Fossa, et al. (1997). "Baseline quality of life of patients with advanced prostate cancer. European Organization for Research and Treatment of Cancer (EORTC), Genito-Urinary Tract Cancer Cooperative Group (GUT-CCG)." Eur J Cancer 33(11): 1809-14

[21] Curran, D., J. P. van Dongen, et al. (1998). "Quality of life of early-stage breast cancer patients treated with radical mastectomy or breast-conserving procedures: results of EORTC Trial 10801. The European Organization for Research and Treatment of Cancer (EORTC), Breast Cancer Co-operative Group (BCCG)." Eur J Cancer 34(3): 307-14

[22] De Boer, J. B., M. A. Sprangers, et al. (1996). "A study of the reliability, validity and responsiveness of the HIV overview of problems evaluation system (HOPES) in assessing the quality of life of patients with AIDS and symptomatic HIV infection." Qual Life Res 5(3): 339-47

[23] de Haes, J. C., D. Curran, et al. (2003). "Quality of life in breast cancer patients aged over 70 years, participating in the EORTC 10850 randomised clinical trial." Eur J Cancer 39(7): 945-51

[24] Douglas, H. R., D. Halliday, et al. (2003). "Economic evaluation of specialist cancer and palliative nursing: Macmillan evaluation study findings." Int J Palliat Nurs 9(10): 429-38

[25] Dudgeon, D. (1992). "Quality of life: a bridge between the biomedical and illness models of medicine and nursing?" J Palliat Care 8(3): 14-7

[26] Fayers, P. and A. Bottomley (2002). "Quality of life research within the EORTC-the EORTC QLQ-C30. European Organisation for Research and Treatment of Cancer." Eur J Cancer 38 Suppl 4: S125-33

[27] Gelber, R. D. and S. Gelber (1995). "Quality-of-life assessment in clinical trials." Cancer Treat Res 75: 225-46

[28] Hardy, J. R., P. Edmonds, et al. (1999). "The use of the Rotterdam Symptom Checklist in palliative care." J Pain Symptom Manage 18(2): 79-84

[29] Heedman, P. A. and P. Strang (2001). "Symptom assessment in advanced palliative home care for cancer patients using the ESAS: clinical aspects." Anticancer Res 21(6A): 4077-82

[30] Holzner, B., G. Kemmler, et al. (2004). "Normative data for functional assessment of cancer therapy-general scale and its use for the interpretation of quality of life scores in cancer survivors." Acta Oncol 43(2): 153-60

[31] Hughes, R., F. Aspinal, et al. (2003). "Professionals' views and experiences of using outcome measures in palliative care." Int J Palliat Nurs 9(6): 234-8

[32] Jarvis, H., F. I. Burge, et al. (1996). "Evaluating 
a palliative care program: methodology and limitations." J Palliat Care 12(2): 23-33

[33] Kaasa, S., K. Bjordal, et al. (1995). "The EORTC core quality of life questionnaire (QLQ-C30): validity and reliability when analysed with patients treated with palliative radiotherapy." Eur J Cancer 31A(13-14): 2260-3

[34] Karnofsky, D. A. (1968). "Determining the extent of the cancer and clinical planning for cure." Cancer 22(4): 730-4

[35] Kiebert, G. M., D. Curran, et al. (1998). "Quality of life after radiation therapy of cerebral low-grade gliomas of the adult: results of a randomised phase III trial on dose response (EORTC trial 22844). EORTC Radiotherapy Co-operative Group." Eur J Cancer 34(12): 1902-9

[36] Klaschik, E. (2000). "[Development and state of palliative treatment in Germany]." Z Arztl Fortbild Qualitatssich 94(7): 538-40

[37] Klee, M., M. Groenvold, et al. (1997). "Quality of life of Danish women: population-based norms of the EORTC QLQ-C30." Qual Life Res 6(1): 27-34

[38] Klepstad, P., J. H. Loge, et al. (2002). "The Norwegian brief pain inventory questionnaire: translation and validation in cancer pain patients." J Pain Symptom Manage 24(5): 517-25

[39] Kobayashi, K., F. Takeda, et al. (1998). "A crossvalidation of the European Organization for Research and Treatment of Cancer QLQ-C30 (EORTC QLQ-C30) for Japanese with lung cancer." Eur J Cancer 34(6): 810-5

[40] Kuenstner, S., C. Langelotz, et al. (2002). "The comparability of quality of life scores. a multitrait multimethod analysis of the EORTC QLQ-C30, SF-36 and FLIC questionnaires." Eur J Cancer 38(3): 339-48

[41] Kyriaki, M., T. Eleni, et al. (2001). "The EORTC core quality of life questionnaire (QLQ-C30, version 3.0) in terminally ill cancer patients under palliative care: validity and reliability in a Hellenic sample." Int J Cancer 94(1): 135-9

[42] Langendijk, J. A., N. K. Aaronson, et al. (2000). "Pretreatment quality of life of inoperable nonsmall cell lung cancer patients referred for primary radiotherapy." Acta Oncol 39(8): 949-58

[43] Mercier, M., J. Bonneterre, et al. (1998). "The development of a French version of a questionnaire on the quality of life in cancerology (Functional Living Index-Cancer: FLIC)." Bull Cancer 85(2): 180-6

[44] Morita, S., K. Shimozuma, et al. (2004). "[Pilottesting of the Japanese version of the EORTC QLQ-STO22 gastric cancer module]." Gan To
Kagaku Ryoho 31(8): 1195-9

[45] Nauck, F., C. Ostgathe, et al. (2000). "[Quality assurance in palliative medicine. Survey of the structure and processing quality in palliative care units in North Rhine-Westphalia in Germany]." Z Arztl Fortbild Qualitatssich 94(7): 587-94

[46] Newbury, J. (2002). "Symptom control outcomes in a community palliative care nursing team." Int $\mathrm{J}$ Palliat Nurs 8(1): 6-12

[47] Osoba, D., B. Zee, et al. (1994). "Psychometric properties and responsiveness of the EORTC quality of Life Questionnaire (QLQ-C30) in patients with breast, ovarian and lung cancer." Qual Life Res 3(5): 353-64

[48] Polit, D. F. and R. E. Sherman (1990). "Statistical power in nursing research." Nurs Res 39(6): 365-9

[49] Schaafsma, J. and D. Osoba (1994). "The Karnofsky Performance Status Scale re-examined: a cross-validation with the EORTC-C30." Qual Life Res 3(6): 413-24

[50] Sprangers, M. A., A. Cull, et al. (1998). "The European Organization for Research and Treatment of Cancer approach to developing questionnaire modules: an update and overview. EORTC Quality of Life Study Group." Qual Life Res 7(4): 291-300

[51] Steer, C. B., G. M. Marx, et al. (2001). "Is there quality in clinical benefit?" Ann Oncol 12(9): 1191-3

[52] Sterkenburg, C. A., B. King, et al. (1996). "A reliability and validity study of the McMaster Quality of Life Scale (MQLS) for a palliative population." J Palliat Care 12(1): 18-25

[53] Stromgren, A. S., M. Groenvold, et al. (2002). "Symptomatology of cancer patients in palliative care: content validation of self-assessment questionnaires against medical records." Eur J Cancer 38(6): 788-94

[54] Stromgren, A. S., M. Groenvold, et al. (2001). "Does the medical record cover the symptoms experienced by cancer patients receiving palliative care? A comparison of the record and patient selfrating." J Pain Symptom Manage 21(3): 189-96

[55] Van Steen, K., D. Curran, et al. (2001). "Sensitivity analysis of longitudinal binary quality of life data with drop-out: an example using the EORTC QLQ-C30." Stat Med 20(24): 3901-20

[56] Vigano, A., N. Donaldson, et al. (2004). "Quality of life and survival prediction in terminal cancer patients: a multicenter study." Cancer 101(5): 1090-8

[57] Ware, J. E., Jr. (1987). "Standards for validating health measures: definition and content." J Chronic Dis 40(6): $473-80$ 
[58] Yun, Y. H., Y. S. Park, et al. (2004). "Validation of the Korean version of the EORTC QLQ-C30." Qual Life Res 13(4): 863-8
[59] Zhao, H. and K. Kanda (2000). "Translation and validation of the standard Chinese version of the EORTC QLQ-C30." Qual Life Res 9(2): 129-37 